\title{
ULISSES E AQUILES REPENSANDO A MORTE (ODISSÉIA XI, 478-491)*
}

\author{
Teodoro Rennó Assunção**
}

RESUMO Breve comentário de um trecho célebre do diálogo entre Ulisses e a psukhé de Aquiles no Hades (Odisséia XI, 478-491), a partir da discussão da hipótese de leitura de Karl Rüter que percebeu aí uma inversão dos papéis tradicionais dos dois heróis em tensão: Ulisses deplorando os sofrimentos do seu nóstos ( «retorno») e exaltando o kléos ( «glória») de Aquiles, $e$ a psukhé de Aquiles, por sua vez, desprezando o seu kléos imperecível e valorizando, face ao estado ínfimo de morto, qualquer forma de vida (mesmo a socialmente mais baixa), ou seja: a continuidade da vida implícita no nóstos.

Palavras-chave: Ulisses, Aquiles, psukhé, Hades.

\begin{abstract}
A brief commentary on a famous passage of the dialogue between Ulysses and Achilles' psyche in the Hades (Odyssey XI, 478-491), based on the discussion of the hypothesis of Karl Rüter who noticed there an inversion of the traditional roles of the two heroes in conflict: Ulysses deplores the sufferings of his nostos ( «regress») and exalts the kleos ( "glory») of Achilles; Achilles' psyche, on its turn, disdains his non-perishable kleos and values, having before him the undermost state of the dead, any form of life (even the lowest in society), that is: the continuity of life implied in the nostos.
\end{abstract}

Key words: Ulysses, Achilles, psyche, Hades.

\footnotetext{
* Texto recebido em abril e aprovado em maio de 2003. Uma primeira versão deste artigo foi lida no XVI Simposio Nacional de Estudios Clásicos realizado em Buenos Aires de 26 a 29 de setembro de 2000.

** Professor de Língua e Literatura Grega (UFMG).
} 
Núcleo gnômico que magnetiza forçosamente a atenção moderna ou contemporânea, este recorte do diálogo entre Ulisses e a psukhé - menos "alma" do que "sombra" — de Aquiles no Hades poderia sem dificuldade ter sido invocado por Nietzsche como imagem para refutar a moralmente duvidosa idéia cristã de que a verdadeira vida - liberta a alma do corpo - começa apenas após a morte, assim como o foi por Freud, em um artigo de 1915 (isto é: em plena guerra) intitulado "Nossa relação com a morte", justamente para mostrar como a princípio a existência post-mortem do defunto não passava de um apêndice, sem substância e valor, da mundana e corpórea vida que experimentamos ${ }^{1}$. Mas é a tensão entre dois modelos de heroísmo que servirá de eixo a nossa interpretação, cuja forma de apropriação de um significado (e da maneira de significar) passará por uma leitura detida e, quando necessário, minuciosa do texto grego em questão. Pois há mais sentidos entre o tex to e suas possíveis leituras do que sonha a nem sempre vã mas certamente aproximativa arte de que dispomos: o comentário textual.

Comecemos então por uma tradução prosaica (que não visa em português nenhuma correspondência rítmica com o hexâmetro dactílico) do núcleo deste célebre diálogo entre Ulisses e a psukhé de Aquiles no Hades:

“ ' Ó Aquiles, filho de Peleu, o mais forte dos Aqueus, vim por necessidade de Tirésias, para que algum conselho ele me dê sobre como eu possa chegar à rochosa Ítaca. Pois ainda não cheguei perto da Acaia, nem sobre minha terra pus os pés, e sempre suporto males; mas do que tu, Aquiles, nenhum homem antes (foi) mais bem-aventurado nem (será) a seguir. Pois antes, estando vivo, te honrávamos como aos deuses, nós os Argivos, por sua vez agora tens amplo poder sobre os mortos, estando aqui; por isto não te aflijas por estar morto, Aquiles.' Assim eu disse, e ele, de imediato retrucando, disse para mim:

'Não me consoles da morte, ilustre Ulisses !

Preferiria, sendo um lavrador, alugar meus serviços a um outro, a um homem sem-lote, que não tem muitos recursos, do que reinar entre todos os mortos já perecidos.' "'2

(Odisséia XI, 478-491)

1 FREUD, Sigmund, "Unser Verhältnis zum Tode" in "Zeitgemässes über Krieg und Tod" in Studienausgabe Band IX. Frankfurt am Main: Fischer Verlag, 1982, p. 52-53. "Nossa atitude para com a morte" in "Reflexões para os tempos de guerra e morte" in Obras psicológicas completas vol. XIV (trad. T. O. Brito, P. H. Britto e C. M. Oiticica). Rio de Janeiro: Imago, 1974, p. 333.

2 O texto grego adotado aqui é o editado por Thomas W. Allen em HOMERI Opera tomi III-IV: Odyssea. Oxford: Oxford University Press, (first edition) 1908, (fifteenth edition) 1987. O texto grego da llíada é o editado por David B. Monro e Thomas W. Allen em HOMERI Opera tomi I-II: Ilias. Oxford: Oxford University Press, (first edition) 1902, (seventeenth edition) 1989. 
A hipótese de leitura destes versos que servirá de ponto de partida para nosso comentário é de Klaus Rüter ${ }^{3}$ : Aquiles e Ulisses, neste diálogo, inverteriam suas posições em relação à escolha do kléos, "glória", ou do nóstos, "retorno", o que resultaria em um jogo irônico de inversões dos próprios elementos que tipificam - opondo-as — as duas personagens: Aquiles, o herói do kléos e da Ilíada, preferindo a vida ou o nóstos de Ulisses ao seu estado de morto no Hades, e Ulisses, o herói do nóstos e da Odisséia, preferindo a morte e o kléos de Aquiles ao sofrimento inumerável de um retorno que parece não ter fim. O primeiro pressuposto desta hipótese é a idéia de que os dois termos, em princípio antagônicos, kléos e nóstos condensariam tematicamente não só as duas personagens — também antagônicas — de Aquiles e de Ulisses, mas ainda os dois fios das estórias contadas pela Ilíada (a glória de Aquiles) e pela Odisséia (o retorno de Ulisses). Como se pode ver desde já, esta engenhosa leitura opera com termos que não estão presentes na passagem da Odisséia que acabamos de traduzir, mas sim na famosa passagem do canto IX da Ilíada (410-416) onde Aquiles diz que sua mãe previu duas formas possíveis e excludentes de morte (dikhthadías kêras) para ele: ou morrer lutando em Tróia e perder o "retorno" (nóstos) mas ganhar a "glória imortal" (kléos áphthiton), ou morrer na terra pátria, tendo retornado à casa (oíkad'híkomi) e vivido ainda muito tempo, mas perder a "nobre glória" (kléos esthlón).

Como bem observou Anthony T. Edwards ${ }^{4}$, a hipótese de uma inversão de posições dificilmente se aplicaria a Ulisses, pois ele jamais é confrontado a uma escolha excludente entre um kléos sem nóstos (isto é: a glória mas morrendo jovem) ou um nóstos sem kléos (isto é: vida longa mas sem glória). De fato, esta incompatibilidade entre "a glória" e "o retorno" diz respeito apenas ao modelo heróico radical (e trágico) de Aquiles — que está longe de ser o único, mesmo na Ilíada. Personagens como Diomedes e Nestor obtêm sua parte de "glória" (kléos) por sua participação corajosa e eficaz na guerra de Tróia (ainda que o kléos do velho Nestor venha não de altos feitos no combate, mas sobretudo da capacidade, apropriada à sua idade, de estabelecer bons planos e de bem deliberar) e conseguem também retornar sãos e salvos às suas respectivas terras pátrias, como o atesta na Odisséia o discurso de Nestor a Telêmaco, relatando o seu retorno e o de Diomedes (cf. Odisséia

3 RÜTER, Klaus, Odysseeinterpretationen: Untersuchungen zum ersten Buch und zur Phaiakis, Hypomnemata 19. Göttingen, 1969, p. 252-253. Ver também NAGY, Gregory, The Best of the Achaeans. Baltimore: The Johns Hopkins University Press, 1979, p. 35-41. E ainda o segundo capítulo "Retour au même: dérive" de PUCCI, Pietro, Ulysse polutropos (trad. J. Routier-Pucci). Lille: Septentrion, 1996 (édition américaine: 1987), p. 181-217.

4 EDWARDS, Anthony T., Achilles in the Odyssey, Beiträge zur klassischen Philologie 171. Königstein/Ts., 1985, p. 51. 
III, 180-183). O caso de Ulisses é mais complexo porque, além da parte de "glória" que ele obtém por sua participação decisiva na guerra de Tróia (é à sua astúcia e não à coragem do então já morto Aquiles que a Odisséia atribui a destruição e o saque desta cidade), a sua "glória" (kléos) na Odisséia inclui como primeiro elemento exatamente as inúmeras provações e sofrimentos que constituem o seu longo e atribulado "retorno" (nóstos), retirando assim a exclusividade do feito guerreiro como critério de atribuição de "glória" e permitindo a proposição de um modelo heróico em que a capacidade de evitar a morte e conservar-se vivo é precisamente o que é celebrado. Por outro lado, Ulisses acabou de saber, por meio de uma revelação de Tirésias (cf. Odisséia XI, 134-137), o modo "ameno" (ablekhrós) de sua morte que após todas as provações, a vingança contra os pretendentes e ainda uma última viagem por terra - ocorrerá "longe do mar" (ex halós), "sob uma velhice opulenta" (gérai húpo liparôi), rodeado por "um povo feliz" (laoí ólbioi). Como bem percebeu Karl Reinhardt, esta morte natural de um Ulisses já velho, opulento e rodeado pelo seu povo então feliz constituirá um contraponto à morte trágica de um Aquiles jovem e que está em terra estrangeira, afastado dos seus familiares e de seu povo. ${ }^{5}$

Diferentemente de A. T. Edwards, pensamos, no entanto, que, no caso de Aquiles, talvez seja possível falar de uma inversão de posições em relação à Ilíada, ainda que tenhamos que precisar melhor em quais termos. Já um escoliasta se perguntava, ao comentar a resposta de Aquiles a Ulisses no Hades (mais precisamente $O d$. XI, 489-491): "Como pode o poeta retratar como um tal amante da vida a personagem que prefere viver brevemente mas com uma boa glória (eúkleia)?” Se, logo após a passagem já citada do canto IX da Ilíada (410-416), Aquiles exprime dramaticamente a intenção de retornar no dia seguinte, não acreditamos que por isto ele estivesse fazendo uma opção pelo "retorno" e renunciando à "glória". Seria preciso ler, em sentido inverso, esta inversão neste ponto da Ilíada como uma dramatização da sua cólera contra Agamemnon, que denuncia precisamente sua inclinação natural pela "glória imortal" (kléos áphthiton) ainda que com a perda do "retorno". Se, por outro lado, é verdade que o móvel principal do retorno de Aquiles ao combate é não o kléos mas a vingança de Pátroclo e a obrigação - uma vez reconhecida a comunidade guerreira de que ele faz parte — que o liga a seus

5 'Achilleus' death is also prophesied. The latter's is as close as Odysseus' is far removed, the one tragic and heartrending, the other among a blessed people. One is in a foreign country, the other is at home not in the sea, not a seaman's death. (...) What a change this is when compared with the Iliad! A 'gentle', natural death, a death in harmony with the gods, is highly praised here." (REINHARDT, K., "The Adventures in the Odissey" - transl. by H. I. Flower - in SHEIN, S. L. (org.), Reading the Odissey: Selected Interpretive Essays. Princeton : Princeton University Press, 1996, p. 114.)

6 Apud EDWARDS, A. T., op.cit., p. 50. 
companheiros de armas ou phíloi, nem por isto Aquiles deixa de fazer uma opção por uma vida breve e uma pronta morte, pois sua mãe lhe anuncia que, logo após a morte de Heitor (o alvo mais imediato de seu desejo), sobrevirá a morte dele (cf. Il. XVIII, 95-96), sem que Aquiles pense um instante sequer em renunciar a esta vingança. A psukhé de Aquiles no Hades parece, porém, colocar abertamente em questão uma opção heróica cuja condição é o sacrifício da própria vida, seja ele determinado pela busca da "glória imortal" ou pelo simples cumprimento dos deveres de reciprocidade impostos pela philótes.

É justamente esta adesão incondicional do Aquiles iliádico ao desejo de vingança ou de glória, sem nenhuma consideração pelo risco de perder a própria existência, o que será usado como modelo de comportamento pelo Sócrates platônico na Apologia de Sócrates ${ }^{7}$, incidindo talvez sobre toda uma tradição de leitura da Ilíada segundo a ótica problematicamente trágica de seu principal protagonista. Mas uma mínima apreciação positiva do fato mesmo de estar vivo, ainda que não implique em princípio em uma desistência covarde do afrontamento da própria morte em combate, pode orientar um comportamento mais flexível que, como o de Ulisses e de outros heróis iliádicos mais "prudentes", leva em consideração as circunstâncias concretas e particulares da ação guerreira, desaconselhando o confronto quando, por exemplo, um deus torna explicitamente manifesto o seu favorecimento do inimigo $^{8}$. A Odisséia, porém, celebra em seu conjunto um herói cuja capacidade básica é a de evitar — por sua astúcia e flexibilidade, ainda que não covardemente - a própria morte, conservando-se em vida e podendo então dar continuidade às sofridas aventuras que se tornarão matéria do canto épico.

7 "Estás em erro, meu amigo, se pensas que um homem, possuidor de algum mérito, deve calcular os riscos de viver ou morrer, em vez de, quando age, considerar apenas se o que faz é justo ou injusto, é obra de um homem de bem ou de um perverso. A acreditar em ti seriam desprezíveis aqueles semideuses que morreram em frente de Tróia, entre outros o filho de Tétis para quem o perigo pouco era em comparação com a desonra." (PLATÃO, Apologia de Sócrates - trad. Manuel O. Pulquério. Lisboa: Edições 70, 1997, p.33. Para o texto grego ver PLATO I, Apology. Cambridge, Massachussetts : Harvard University Press, 1995 - eighteenth edition, p. 104.) É certo que o argumento subseqüente da incognoscibilidade da experiência do estar morto é em si totalmente pertinente - colocando em questão não só a representação homérica do post-mortem, mas também as próprias fabulações platônicas do Fédon mas as conseqüências éticas que dele retira o Sócrates platônico são inteiramente discutíveis, pois a incerteza quanto à existência de algo após a morte poderia levar precisamente a uma valorização da vida análoga à que resulta de uma representação "pessimista" do morto tal como a do Hades homérico.

8 "Estas circunstâncias na llíada designam uma rede complexa de relações entre os adversários mortais; uma rede cujas coordenadas são sempre determinadas pelo jogo, obscuro e incognoscível para o herói, das intervenções divinas. Este conjunto (...) se distingue dos processos naturais pelo fato de ser algo mutável e imprevisível. É nestas circunstâncias que o mortal age e ele não pode ignorá-las. O que a multiplicidade das cenas guerreiras parece pois nos revelar é que (segundo uma linguagem aristotélica) não basta ser corajoso, mas é preciso saber ainda onde, quando e com quem se deve sê-lo." (ASSUNÇÃO, Teodoro Rennó, "Nota crítica à bela morte vernantiana", CLASSICA 7/8. São Paulo, 1994/1995, p. 55.) Para uma demonstração mais detida deste argumento ver o conjunto deste mesmo artigo. 
Detenhamo-nos agora com mais vagar na tão comentada contradição entre a resposta da psukhé de Aquiles a Ulisses e sua opção iliádica por uma morte heróica e "a glória imortal". O comentário de Jean-Pierre Vernant sobre a resposta da psukhé de Aquiles a Ulisses visa precisamente dissolver a pretensa crítica à morte heróica aí contida, ao considerar que esta crítica apenas existiria "(...) se a sobrevida gloriosa estivesse localizada para os Gregos no reino dos mortos, se a recompensa da morte heróica fosse a entrada do defunto no Paraíso e não a presença continuamente mantida de sua lembrança na memória dos homens." Mas mesmo que admitíssemos — coincidindo com a leitura que J.-P. Vernant faz da resposta de Aquiles — que a única vida existente é a dos vivos e que a glória, portanto, é ser lembrado pelos vivos, nem por isto a psukhé de Aquiles deixaria de marcar que para um morto pouca diferença faz o que os vivos digam sobre ele, que a glória e o poder são enfim indiferentes ao fato mesmo de estar morto que, este sim, poderia ser trocado - mesmo tendo sido o preço da glória — até mesmo pela forma mais miserável de existência. Como observou pertinentemente Nicole Loraux, “ (...) vista do outro lado do limiar, a morte não é nem valor nem desejável em si." 10

Mas, em vez de antecipar apressadamente a orientação que tomará nosso comentário, talvez fosse mais prudente olharmos com atenção os termos mesmos em que este diálogo está sendo travado. A nossa primeira surpresa é constatar que aí nenhuma alusão é feita a uma morte heróica. As palavras de Ulisses são: “(...) antes, estando vivo, te honrávamos como aos deuses,/ nós os Argivos, por sua vez agora tens amplo poder sobre os mortos,/ estando aqui (...)."(Od. XI, 484-486). Já as da psukhé de Aquiles dizem: "Não me consoles da morte, ilustre Ulisses!/ Preferiria, sendo um lavrador, alugar meus serviços a um outro,/ a um homem sem-lote, que não tem muitos recursos,/ do que reinar entre todos os mortos já perecidos."(Od. XI, 488-491).

Se o termo "morte" (thánaton) é usado pela psukhé de Aquiles, ele não é acompanhado por nenhum adjetivo e parece se referir não à maneira particular como ele mesmo morreu, mas ao mero e ordinário fato de estar morto. Neste diálogo — assim como na fala de Agamemnon na segunda Nékuia nada ouvimos sobre as circunstâncias da morte de Aquiles, não estando pois diretamente em questão a sua heroicidade. O que parece, porém, suficientemente indicado é o poder que Aquiles teria sobre os mortos (nekúessi), poder expresso tanto pelo verbo kratéeis ("tens poder sobre") usado por Ulisses

9 VERNANT, Jean-Pierre, "Mort grecque: mort à deux faces" in L'individu, la mort, l'amour. Paris: Gallimard, 1989, p. 87.

10 LORAUX, Nicole, "Le point de vue du mort", Po\&sie 57. Paris, 1991, p. 74. 
quanto pelo verbo anássein ("reinar") usado pela psukhé de Aquiles. Ora, se a indicação do poder é explícita, o seu sentido mesmo é pouco preciso, pois nada nos é dito de uma hierarquia de poder entre os mortos, senão daquela sabida e elementar - que faz de Hades e Perséfone os soberanos deste reino. Estaria então este poder de Aquiles entre os mortos, tal como percebido por Ulisses, referido à sua reputação de "melhor guerreiro entre os Aqueus"? Um primeiro deslocamento, sensível aí, estaria no fato de que seu poder viria de sua excelência guerreira e não de seu estatuto político, como é o caso de Agamemnon na Ilíada. Mas, mais elementarmente ainda, um tal poder proviria da imagem de "melhor guerreiro" que Aquiles tinha entre os Aqueus enquanto vivo e da qual os mortos - contrariamente ao que propõe J.-P. Vernant - conservariam então alguma memória. Pois se não é desta imagem à qual Ulisses se refere abertamente ao chamar Aquiles de "o mais forte dos Aqueus" (méga phértat'Akhaiôn) —, de onde então viria este poder de Aquiles entre os mortos?

Mas antes do que conjecturar sobre alguma outra e improvável estória de Aquiles no Hades, deveríamos agora considerar mais atentamente o próprio conteúdo da resposta de Aquiles a Ulisses. Pois a resposta de Aquiles visa, a partir do conhecimento adquirido pela experiência mesma da morte e do estar morto, corrigir uma falsa apreciação de Ulisses sobre o valor do seu pretenso poder sobre os mortos (méga kratéeis nekúessin). Ela opera a partir da destituição de qualquer pertinência de um modelo de poder e consideração entre os vivos aplicado a um reino cuja infra-qualidade ontológica resiste a qulquer tentativa de valorização. A impaciência contida no imperativo (mè dé moi thánatón ge paraúda) não é apenas uma característica do temperamento de Aquiles, mas resulta de um saber sobre a morte que não se deixa mais iludir por nenhum consolo ou amenização.

Para demonstrar este estatuto infra-ontológico de uma psukhé ("sombra") no Hades - isto é: a impossibilidade de compará-lo a qualquer forma de vida sobre a terra - Aquiles oporá dois estatutos sociais extremos: o mais baixo entre os vivos e o mais alto entre os mortos, exprimindo desde já sua preferência pela vida, mesmo a de um lavrador assalariado a serviço de um homem sem muitos recursos. Para uma definição mais precisa deste estatuto social os termos decisivos são o adjetivo epárouros e o verbo theteuémen. Para Alfred Heubeck e Arie Hoekstra epárouros (eón) "provavelmente significa apenas 'alguém que vive da terra' antes que 'servo', uma vez que está em aposição a nekúessi (e enthád'eón 486)" "11. Esta definição corrige a do Lexi- 
con de Liddell \& Scott: "attached to the soil as a serf", não deixando de sugerir também o aspecto de "terra cultivada", "cultura", presente em árou$r a$, e vertido explicitamente tanto na última definição do Lexicon Homericum de Ebeling: "rusticus, agricola" quanto na do Dictionnaire de Bailly: "cultivateur". theteuémen é um infinitivo homérico em -men do verbo theteúo "servir como um thés" que, segundo Heubeck e Hoekstra, "é aparentemente um homem livre que recebe pagamento (XVIII 356-7) por um trabalho ocasional (theteúei)." ${ }^{12}$ Este homem aluga sua força de trabalho para um outro que é ákleros "privado de um lote (klêros) de terra ou de herança" alguém, pois, sem sorte - e "que não tem muitos recursos" (hôi mè bíotos polùs eíe). Este homem portanto - como dizem bem Heubeck e Hoekstra, resumindo Moses I. Finley - "é considerado como estando no mais baixo degrau da escala social, mais do que um escravo que ao menos pertence a uma estrutura doméstica." ${ }^{13} \mathrm{Se}$, como sugere M. I. Finley, um assalariado este thés -, e não um escravo, era para Aquiles a mais inferior das criaturas terrestres, por não pertencer a nenhuma estrutura doméstica e estar portanto desconectado $^{14}$ (o que lembra a situação de um errante ou exilado como na imagem da pior das opções para os mortais no discurso de Aquiles a Príamo sobre os dois jarros de Zeus, cf. Il. XXIV, 531-533), nem por isto ele condicionará o valor da vida à sua qualidade social. Para a psukhé de Aquiles a servidão (ou uma situação social ainda mais penosa) não seria pois uma razão suficiente para alguém preferir a morte à vida. Este amor incondicional de Aquiles à vida - que como a covardia seria considerado signo de servilismo - poderia espantar um guerreiro ou cidadão grego. ${ }^{15}$ Expressaria este amor ou esta saudade uma visão inteiramente positiva da vida de um humano sobre a terra?

Se atentarmos para o que diz a psukhé de Aquiles em sua primeira fala a Ulisses, veremos que, se ele lamenta e caracteriza negativamente o seu estado de morto, nem por isto ele caracterizará positivamente a vida. Pois os mortais (brotôn) ali são caracterizados como kamónton, um particípio aoristo do verbo kámno. Ora, se um dicionário como o de Pierre Chantraine dá o sentido do aoristo deste verbo como, por eufemismo, o de "estar morto", o primeiro sentido - intransitivo - é o de "cansar-se, estar cansado, sofrer, ser infeliz"16. E dificilmente o sentido aqui para caracterizar as psukhaí seria

12 HEUBECK, A. and Hoekstra, A., op.cit.,, p. 106.

13 Ibidem. Curiosamente, Ulisses - já em İtaca, mas ainda não podendo se revelar como tal - assume, antes da vingança, a identidade de um mendigo (ptokhós), outra figura homérica da inferioridade social extrema.

14 Cf. FINLEY, Moses I., The World of Odysseus. New York: Pelican Books, 1979 - first edition 1954 -, p. 57-58.

15 Cf. ARENDT, Hannah, Condition de l'homme moderne, trad. G. Fradier. Paris: Calmann-Lévy, 1983, p.45.

16 Cf. CHANTRAINE, Pierre, Dictionnaire étymologique de la langue grecque vols. 1-2. Paris: Klincksieck, 1983, p.410. 
o de "simulacros" (eídola) de "mortais mortos" (kamónton), pois uma psukhé no Hades supõe evidentemente a morte do ser de que ela é apenas um simulacro. O particípio kamónton sugere portanto uma representação da vida humana que parece coincidir com aquela que Ulisses tem de seu próprio nóstos ao dizer que "sempre suporto males" (aièn ékho kaká) e que já aparece anunciada pelo poeta na abertura do poema quando Ulisses é definido como "o que errou inumeravelmente" (hós mála pollà plágkhthe) e "o que sofreu muitas dores no mar" (pollà d'hó g'en póntoi páthen álgea) (Od. I, 1-2 e 4).

É portanto apenas em relação à infra- ou quase não existência de um morto que a vida de um "mortal que se cansa ou sofre" pode ser considerada um bem, mesmo aquela de um assalariado (thés) a serviço de um homem sem-lote e sem muitos recursos. O que caracterizaria então esta negatividade absoluta do estado de morto? Aquiles, retomando de algum modo a descrição já apresentada neste mesmo canto, dirá que os mortos (nekroî) são aphradées "insensíveis" e eídola "simulacros" dos mortais que se cansam. Em aphradées temos a indicação da ausência do phrázesthai, "da capacidade de pensar ou refletir", ou ainda mais elementarmente "da capacidade de perceber". Como se os mortos - ou ao menos aqueles que não foram revitalizados pelo sangue dos animais sacrificados por Ulisses - fossem incapazes de reconhecer ou de se lembrar do que quer que seja, estando portanto privados não só de sua própria identidade, mas de uma consciência qualquer do mundo e da existência. Mas, mais do que isto, eles são apenas eídola, "imagens" ou "simulacros", dos mortais vivos que eles um dia foram. Isto é: falta a eles a substância da carne, a corporeidade, a capacidade de tocar e ser tocado, como já o demonstrara bem a cena em que Ulisses tenta em vão abraçar a psukhé de sua mãe (Od. XI, 204-224). É como se, para Homero, no sentido do tato fosse concentrado o critério último para a determinação da realidade de algo. ${ }^{17}$

A incapacidade de perceber ou pensar, juntamente com a incapacidade de tocar ou ser tocado, retira aos mortos o que poderíamos chamar - sem nenhuma pretensão de formular uma teoria homérica do conhecimento - de fundamentos mínimos de realidade. É como se a ausência de consciência ou de sentido táctil subtraísse a própria existência - ou ao menos aquilo que nós vivos reconhecemos como tal - aos mortos. Ora, a ausência destes fundamentos mínimos - que, como vimos, não impedem que a existência em seu conjunto seja considerada como sofrimento (ainda que sejam também

17 Sobre o tato em Aristóteles como o mais básico de todos os sentidos e como índice de realidade material, ver FREELAND, Cynthia, "Aristotle on the sense of touch" in NUSSBAUM, Martha C. \& RORTY, Amélie O. (orgs.), Essays on Aristotle's De Anima. Oxford: Clarendon Press, 1992. Esta curiosa aproximação - que faz parte de uma série de outros pontos de contato entre estes dois universos também tão distintos de pensamento: Homero e Aristóteles, e que deve obviamente ser feita com alguma atenção às óbvias diferenças de formulação e de contexto - me foi sugerida generosamente por Cláudio William Velloso. 
eles que permitam que um prazer qualquer tenha lugar) — será, em uma última instância que é sem dúvida afirmativa, considerada como um mal pior do que a pior das formas de existência em que eles ainda estejam conservados. Em meio à percepção — tão própria da Ilíada quanto da Odisséia — da vida como sofrimento, a existência enquanto tal será afirmada de maneira elementar e incondicional pela psukhé de Aquiles, o que talvez pareça mais próprio à Odisséia do que à Ilíada para aqueles que ainda lêem esta última segundo a perspectiva parcial de um Aquiles partidário da morte. 